\title{
Proposta de Caracterização Petrofísica de Litofácies da Formação Pirabas
}

*Figueiredo, B. P, UFPA

Copyright 2018, SBGf - Sociedade Brasileira de Geofísica

Este texto foi preparado para a apresentação no VIII Simpósio Brasileiro de Geofísica, Salinópolis, 18 a 20 de setembro de 2018. Seu conteúdo foi revisado pelo Comitê Técnico do VIII SimBGf, mas não necessariamente representa a opinião da SBGf ou de seus associados. É proibida a reprodução total ou parcial deste material para propósitos comerciais sem prévia autorização da SBGf.

\section{Abstract}

This work consists in the creation of a methodology for the petrophysical analysis of samples of rocks from the Pirabas formation, analyzing specifically the sandstone and carbonate rocks. In addition, the study of the mineralogical composition to also obtain a petrographic characterization. The objective of this study was to collect data on gamma ray profiles, neutron porosity, density, sonic, resistivity and mineralogical composition. The proposed classification of samples: (1) reservoir-negative properties, (2) reservoir-positive properties and (3) reservoir-undefined properties.

\section{Resumo}

Este trabalho discute uma proposta de criação de uma metodologia para análise petrofísica de amostras de rochas da formação do Pirabas, analisando especificamente as rochas areníticas e carbonáticas. Visa-se a uma caracterização petrográfica com o auxílio de levantamento de dados de perfis de raios gama, porosidade neutrão, densidade, sônico e resistividade. As amostras serão classificadas como: (1) propriedades reservatório-negativo, (2) propriedades reservatóriopositivo e (3) propriedades reservatório-indefinido.

\section{Introdução}

O presente trabalho compreende o estudo de rochas areníticas e carbonáticas para determinar o potencial como reservatório de hidrocarbonetos da Formação Pirabas, localizada no Estado do Pará e aflorante no município de Salinópolis. Para isso, está prevista a utilização de métodos indiretos para análises petrofísicas, em termos de capacidade de armazenagem de hidrocarbonetos. A respeito disso, a literatura é carente de estudos sobre o assunto para a região.

Os parâmetros de estudo propostos são: a saturação de fluidos, densidade da rocha, volume de argila e no intuito de complementar estas, obter informações texturais e mineralógicas das litofácies, obtendo-se assim também uma caracterização petrográfica.

\section{Metodologia}

O estudo das amostras da Formação Pirabas terá por base conceitos de caracterização de propriedades petrofísicas (Rosa et al, 2011) conjuntamente com uma caracterização petrográfica (Suguio, 2003) e a utilização da ferramenta da perfilagem geofísica (Stevanato,2011) e (Nery, 2004). As duas últimas referências essenciais na indicação de propriedades de rochas reservatório e amplamente utilizadas na investigação de poços.

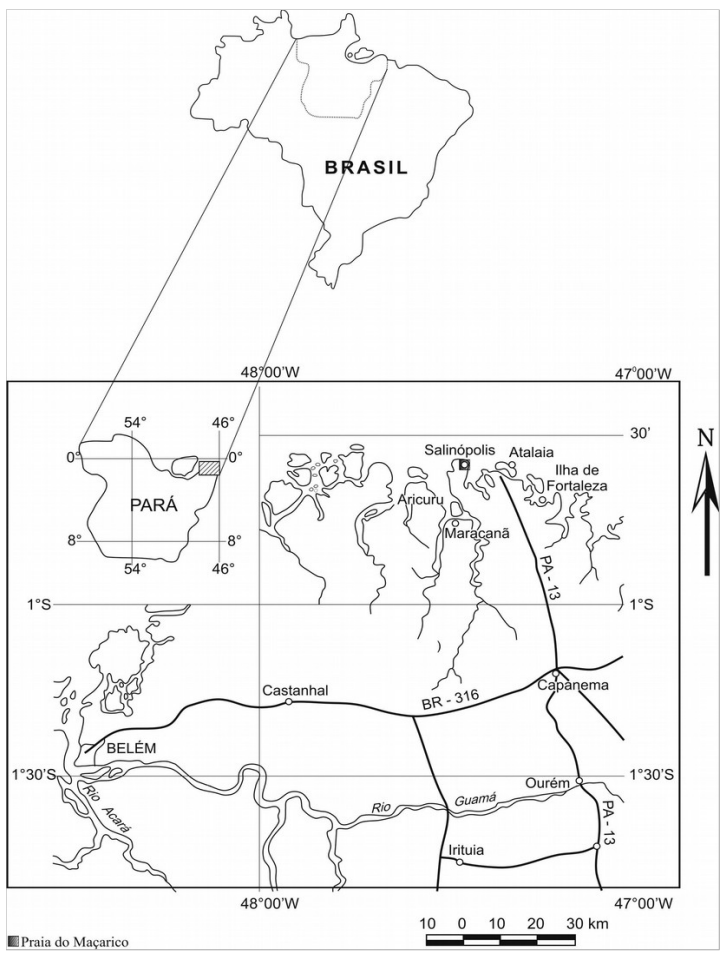

Fonte: Távora, V. A. et al. 2013

Discussão

A Formação Pirabas necessita de mais estudos sobre possibilidade de haver rochas com propriedades para armazenagem de hidrocarbonetos. No momento, é vista como fornecedora de matéria-prima para indústria de cimento. Os estudos também são importantes do ponto de vista ambiental, pois podem auxiliar na limitação das áreas de exploração nas avaliações custo-benefício.

\section{Referências}

ROSA et al. (03 co-authors), 2011. Engenharia de Reservatórios de Petróleo.

STEVANATO, 2011. Análise Petrofísica de Reservatórios. Universidade Estadual de Campinas

NERY, 2004. Perfilagem geofísica

SUGUIO, 2003. Geologia Sedimentar 
JUNIOR, 2016. Controles Deposicionais e diagenéticos das propriedades petrofísicas dos reservatórios aptianos/barremianos do grupo lagoa feia no norte da bacia de campos. Universidade federal do rio grande do sul.

TÁVORA, V. A. et al, 2013. Geologia e paleontologia do biohermito da Formação Pirabas(Mioceno Inferior).Geology and paleontology of the reef facies of the Pirabas Formation (Early Miocene). Revista do Instituto de Geociências - USP

KLEIN et al, 2007. Cimentação Carbonática em Reservatórios Siliciclásticos- O Papel da Dolomita. Universidade Federal do Rio Grande do Sul

DANDEKAR, 2013. Petroleum Reservoir Rock and Fluid Properties.

AHR, 2008. Geology of Carbonate Reservoir

JUNIOR, 2017. Utilização da Perfilagem de Poços para a Caracterização Geofísica do Campo de Namorado. Universidade Federal do Rio Grande do Norte.

BECKER, 2014. Caracterização Petrográfica e Petrofísica de Litofácies Vulcânicas da Formação Serra Geral. Universidade Federal De Santa Catarina. 